\title{
What Do Partners Share in Strategic Alliances?
}

\author{
Lee $\mathrm{Li}$ \\ York University, 4700 Keele St. Toronto, Canada \\ Leeli@yorku.ca
}

\begin{abstract}
This study categorizes resources into firm-specific and general resource; costs into accounting and non-accounting cost; and risks into visible and invisible risks. Using data from 167 Canadian firms in technology industries, we find that sharing firm-specific resources and non-accounting costs are negatively correlated with environmental dynamism but sharing general resources, accounting costs and visible risks are positively correlated with environmental dynamism. Findings suggest that sharing certain resources, costs and risks do not necessarily incur high transaction costs.
\end{abstract}

Keywords: Strategic alliances, Environmental dynamism.

\section{$1 \quad$ Introduction}

What do partners share in their strategic alliances? The mainstream management literature suggests that they share resources, costs and risks [1]. However, the literature also acknowledges that such sharing increases transaction costs which are positively correlated with environmental dynamism [2]. The costs include partner opportunism, coordination costs, equity hostage and dependence, etc. Empirical studies show that these costs, under certain conditions, can surpass benefits provided by strategic alliances and may even make partners' R\&D and production activities unproductive. As such, an important question emerges as to why partners share resources, costs and risks even at such high transaction costs. A logical answer to the question would be the possibility that partners share different resources, costs and risks in diverse environments to minimize the transaction costs and maximize the sharing benefits. However, the existing studies do not differentiate between these resources, costs and risks and associate them with sharing costs and sharing environments.

This paper aims to make such contributions. It develops and tests the hypotheses that both the costs and the benefits of sharing depend, to a great extent, on categories of resources, costs and risks that partners share and the environments within which such sharing occurs. In a highly dynamic market, for example, the costs of sharing knowledge resources between technology-based partners may be much higher than the costs of sharing financial resources between the same partners. The partners can specify how they share the risks and costs when they share financial resources in the contract but they can hardly determine accurately the partner's opportunistic behavior 
in sharing the knowledge resources and the impacts of environmental dynamism on such sharing. This study will differentiate between these resources, costs and risks and clarify the relationships between the benefits and the cost of sharing against the background of environmental dynamism.

In this study, we define resources as assets that are tied semipermanently to a firm; costs as the sacrifice a firm makes to achieve a particular purpose; and risks as negative variance in performance beyond the control of decision makers. Accordingly, we classify resources, costs and risks, each into two categories: resources into firm-specific and general resources; costs into accounting costs and non-accounting costs; and risks into visible and invisible risks. Firm-specific resources are those unique to a particular firm while general resources are those available in the market. Accounting costs include operation costs, such as fixed and variable costs, which are specified in firms' income statements. Non-accounting costs are those costs unidentified in firms' income statements, including transaction costs and opportunity costs. Visible risks are the possibilities predicted and specified in the partnership contracts while invisible risks are those unspecified in the contracts.

Evidence collected in this study shows that partners share firm-specific resources and non-accounting costs in a relatively stable environment. In contrast, they share general resources, accounting costs and visible risks when environments grow highly dynamic. The findings of this study make significant contributions to the existing literature on two fronts. First, it clarifies the fact that the benefits and the costs of sharing resources, costs and risks between partners depend on the types of resources, costs and risks they share and the environments within which the sharing occurs. Second, it explains why firms use strategic alliances even when sharing resources, costs and risks may lead to high transaction costs.

\section{Hypotheses Development}

\subsection{Firm-Specific and General Resources}

Research-based view (RBV) suggests that firms' ability to sustain their competitive advantage is based on their firm-specific resources which are not easily tradable or redeployable outside the firm and thus are difficult for competitors to imitate [3]. Firm-specific resources include property based resources and knowledge-based resources. Property-based resources are protected by property rights while knowledge-based are protected by knowledge barriers which are subtle, hard-tounderstand, or built on accumulation of experiences and knowledge, and continuous financial and human investments [4].

Partners may share property-based and knowledge-based resources through licensing/franchising, joint ventures or $R \& D$ consortia. In other words, partners give up, to varying degrees, the property rights or knowledge barriers in partnership cooperation. Therefore, the firms who own the property-based and knowledge-based resources have to use partnership contracts to safeguard the value of these resources in order to maximize its economic rents from alliances and sustain the value of these resources. Environmental dynamism makes such safeguards difficult because, with 
the ambiguity associated with the environmental dynamism, partners can hardly specify each partner's responsibilities and obligations in the contracts [5]. Monitoring partners' behavior is difficult in a highly dynamic environment. Moreover, sharing property-based and knowledge-based resources is a firm-specific investment and such investments have, by definition, limited economic value in alternative settings. If the alliance agreements are terminated unexpectedly due to the environmental changes, firms can hardly recoup their initial investments.

General resources are different from firm-specific ones in that general resources are subject to ready imitation by other firms. Capital, land and unskilled labor are examples of general resources. Environmental dynamism provides a flow of opportunities that typically is fast, complex, ambiguous, and unpredictable [6]. Firms may not have sufficient general resources under their direct control to exploit these opportunities. Direct control over abundant general resources results in inflexibility which makes firms inefficient to manage the complexities and ambiguity. Strategic alliances enable these firms to get access to external general resources. Through joint venture in foreign countries, for example, partners can have access to local production infrastructure and low-cost labor. Sharing general resources rather than owning general resources provides important strategic benefits, such as loose coupling, ambidexterity and improvisation, which increase firms' learning speed and responsiveness to manage environmental dynamism More importantly, sharing general resources reduces investment risks. As such, firms tend to get access to these resources through strategic alliances when they experience high environmental dynamism. Accordingly, we predict that:

Hypothesis la: The higher the environmental dynamism, the more general resources partners will share.

Hypothesis 1b: The higher the environmental dynamism, the fewer firm-specific resources partners will share.

\subsection{Accounting Costs and Non-accounting Costs}

Environmental dynamism raises firms' accounting costs because the dynamism leads to both opportunities and threats, and managing increased opportunities and threats incurs accounting costs. Partners may not have sufficient financial resources to cover the costs on their own. More importantly, unexpected accounting costs may increase substantially in dynamic environments due to the high unpredictability and velocity and sourcing from partners is an effective way to manage such sharp cost fluctuations. Sourcing cash from partners, for example, is a frequently used option for firms in high-tech industries. Because accounting costs are specified in numbers, both parties' responsibilities and obligations in sharing these costs can be relatively precisely defined in partnership contracts. In other words, transaction costs for such sharing is minimal.

Non-accounting costs include transaction costs and opportunity costs. Nonaccounting costs are mutual between partners. Both partners share such costs when they form strategic alliances. Existing studies have shown that both parties may earn 
private benefits unilaterally from the alliance [7]. Such private benefits vary from cheating to learning by observation without other party's permission. Consequently, both partners have to monitor each other's behavior to reduce the possibilities of opportunism because both partners invest in the alliances and they have to protect such partner-specific investments.

High levels of environmental dynamism not only increase non-accounting costs but also make the non-accounting cost forecasting inaccurate. Dynamism creates the causal ambiguity which blurs the links between non-accounting costs and the effectiveness to reduce transaction costs and opportunity costs, and many contingencies will distort cost estimates [8]. Because accurate cost forecasting is difficult to achieve, partners have to identify and correct their forecasting problems by frequently re-estimating and reallocating costs between them. Such frequent reestimation and reallocation not only make existing partnership agreements nonbinding, but also create enormous uncertainties for the future of these agreements. Accordingly, we predict that:

Hypothesis 2a: The higher the environmental dynamism, the more accounting costs partners will share.

Hypothesis 2b: The higher the environmental dynamism, the less non-accounting costs partners will share.

\subsection{Visible and Invisible Risks}

Visible risks are the possibilities that a hazard may occur in a decision-maker's perception. In other words, they can be defined and specified in partnership contracts [9]. When partners jointly develop a new product, for example, they may predict the possible failure of the new product. Invisible risks are unforeseeable risks. For example, the sudden death or resignation of a firm's CEO may cause sharp fluctuations in the firm's stock value. Because of such unforeseeablity and unexpectedness, invisible risks can hardly be specified and each party's responsibility and obligations in sharing these invisible risks can hardly be clearly determined in the partnership contracts.

Environmental dynamism increases both visible and invisible risks. However, its impacts on these risks are different. Environmental dynamism enhances partners' desire to share the visible risks because the dynamism increases the risks and the costs to cover the risks [10]. Firms may not have sufficient resources, such as cash, to manage these risks on their own [11]. More importantly, the responsibilities and obligations to share risks between partners can be specified in partnership contracts so the possibilities of partner opportunism are minimal [12].

Because the invisible risks are unforeseeable, the responsibilities and obligations in sharing invisible risks are mainly based on partners' mutual trusts [13]. However, existing studies have shown that such trusts are negatively correlated with environmental dynamism. Generally, firms share invisible risks only when they are confident that the risk-adjusted returns of a joint project will be positive [14]. High levels of environmental dynamism may reduce or even damage the confidence 
because risk forecasting and measurements become highly inaccurate, if not impossible, in such environments. Accordingly, we predict that:

Hypothesis 3a: The higher the environmental dynamism, the more visible risks partners will share.

Hypothesis 3b: The higher the environmental dynamism, the less invisible risks partners will share.

\section{$3 \quad$ Method}

\subsection{Setting, Sample, and Data}

This study used data of Canadian technology firms to test the hypotheses. Two waves of questionnaires were mailed to the CEOs or the highest-ranking officers of the target firms. All questions in the questionnaires were presented as a seven-point Likert-type scale (ranging from $1=$ strongly disagree to $7=$ strongly agree).

\subsection{Main Variables}

Firm-specific resources consist of five measurement items: (1) patents; (2) expertise in making a product; (3) possession of a unique technology; (4) skilled labor; and (5) brand equity. General resources are composed of four measurement items: (1) cash; (2) production and storage infrastructure; (3) unskilled labor; and (4) communication/transportation/distribution facilities. Accounting costs include: (1) prime costs; (2) conversion costs; and (3) non-manufacturing costs. Non-accounting costs are composed of both transaction costs and opportunity costs. Measurement items of transaction costs include (1) monitoring/controlling costs; (2) coordination costs; (3) information collecting/processing costs; (4) partner maximizing unilateral interests; and (5) partner cheating. Measurement items of opportunity costs include (1) the loss of other market opportunities; (2) failure to address other threats; and (3) loss of possible profits in other business. Measurement items of visible risks consist of (1) magnitude of possible loss; (2) chances of possible loss; and (3) exposure to possible loss. Measurement items of invisible risks include (1) feelings that unfavorable hazards would occur; (2) the perceived possibilities that unknown unfavorable hazards would occur; and (3) past experiences that unfavorable hazards which were undefined in partnership contracts occurred when contracts were executed.

We used a composite index of four items to measure sharing of each abovementioned category between partners. These four items include necessity, magnitude, duration, and possible impacts of sharing. Measurement of environmental dynamism (EV) was based on the items developed by Boyd and associates (1993) and Zahra and associates (1997), and there were seven such items that compose the construct (see Appendix 1). Both linear and squared terms of the variable $\left(\mathrm{EV}\right.$ and $\left.\mathrm{EV}^{2}\right)$ were used to denote low and high levels of environmental changes. All data will be provided upon request. 


\section{Discussion and Conclusions}

The evidence collected in this study indicates that sharing firm-specific resources and non-accounting costs is feasible at low level of environmental dynamism. In other words, a low level of environmental dynamism does not impede such sharing. When environmental dynamism grows high, however, sharing firm-specific resources and non-accounting costs becomes unlikely. In contrast, partners share general resources, accounting costs and visible risks in a highly dynamic environment. It should be noted that sharing invisible risks between partners may not be affected by the levels of environmental dynamism. Two possible interpretations emerge from this study. Frist, invisible risks increase substantially when environments grow dynamic. As such, partners have to share more invisible risks if they want to keep their partnerships. Second, it is difficult for managers to define invisible risks regardless of the level of environmental dynamism and they cannot negotiate and specify such risks in the partnership contracts. Consequently, they do not have a clear idea of how to deal with such risks. Perhaps both causes co-exist and they work in combination.

The findings of this study have important theoretical implications. First, partners share more general resources, accounting costs and visible risks when environments grow dynamic. As such, sharing general resources, accounting costs and visible risks may not necessarily increase transaction costs and increased environmental dynamism enhances the needs for partners to share general resources, accounting costs and visible risks. The evidence explains why firms use strategic alliances in highly dynamic environments. Transaction costs are associated not only with environmental dynamism but also with the nature of the resources, costs and risks that partners share. Second, sharing firm-specific resources and non-accounting costs between partners decreases with environmental dynamism. The evidence confirms the traditional belief that sharing firm-specific resources incurs transaction costs in dynamic environments. Moreover, such sharing may also increase opportunity costs which have been ignored in the mainstream literature. Both transaction costs and opportunity costs vary positively with environmental dynamism and both of them are sacrifice partners make in their partnerships. Transaction costs have been widely discussed in the existing literature but opportunity costs do not receive a similar attention. Finally, in contrast to the existing literature, partners are willing to share more visible risks when environments are dynamic. Even their sharing of invisible risks may not necessarily decrease in highly dynamic environments. In other words, the traditional belief that environmental dynamism is negatively correlated with partners' wishes to share risks may not be true.

\section{References}

1. Borch, O.J., Huse, M., Senneseth, K.: Resource configuration, competitive strategies, and corporate entrepreneurship: An empirical examination of small firms. Entrepreneurship Theory and Practice 24(1), 49-70 (1999)

2. Das, T., Teng, B.: Strategic alliance constellations: A social exchange perspective. Academy of Management Review 27, 445-456 (2002) 
3. Glover, S.I., Wasserman, C.M.: International strategic alliances, joint Ventures \& strategic alliances. Law Journal Press, The US (2003)

4. Goerzen, A.: Alliance networks and firm performance: The impact of repeated international strategic alliances. Strategic Management Journal 28, 487-509 (2007)

5. Gulati, R., Khanna, T., Nohria, N.: Unilateral commitments and the importance of process in alliances. Sloan Management Review 35(3), 61-69 (1994)

6. Lecocq, X., Demil, B.: Strategizing industry structure: The case of open systems in a lowtech industry. Strategic Management Journal 27, 891-898 (2006)

7. Ireland, R.D., Hoskisson, R.E., Hitt, M.A.: The management of strategy: Concepts and cases. South-Western, Mason (2009)

8. Dess, G.G., Beard, D.W.: Dimensions of organizational task environments. Administrative Science Quarterly 29(1), 52-73 (1984)

9. Qian, G., Li, L.: Profitability of small- and medium-sized enterprises in high-tech industries: The case of the biotechnology industry. Strategic Management Journal 24(9), 881-887 (2003)

10. Lu, J.W., Beamish, P.: The internationalization and performance of SMEs. Strategic Management Journal 22, 565-586 (2001)

11. Amburgey, T.L., Kelly, D., Barnett, W.: Resetting the clock: The dynamics of organizational change and failure. Administrative Science Quarterly 38, 51-73 (1993)

12. Hannan, M.T., Freeman, J.: Structural inertia and organizational change. American Sociological Review 49, 149-164 (1984)

13. Baum, J., Calabrese, T., Silverman, B.: Don't go it alone: alliance network composition and startup's performance in Canadian biotechnology. Strategic Management Journal 21, 267-294 (2000)

14. Luo, Y.: Are joint venture international strategic alliances more opportunistic in more volatile environment? Strategic Management Journal 28, 39-60 (2007) 